\title{
Giant cell tumor of bone arising in long bones possibly originates from the metaphyseal region
}

\author{
NAOHISA FUTAMURA, HIROSHI URAKAWA, SATOSHI TSUKUSHI, \\ EISUKE ARAI, EIJI KOZAWA, NAOKI ISHIGURO and YOSHIHIRO NISHIDA
}

Department of Orthopedic Surgery, Nagoya University Graduate School of Medicine, Nagoya, Aichi 466-8550, Japan

Received January 7, 2015; Accepted February 4, 2016

DOI: $10.3892 / \mathrm{ol} .2016 .4264$

\begin{abstract}
Giant cell tumor of bone (GCTB) is a primary benign bone tumor with a locally aggressive character. Definitive descriptions of the site of origin for this type of tumor are not available. The aim of the present study was to evaluate the site of origin of GCTB of long bones with regards to epiphyseal lines by means of radiographic examination. For that purpose, plain X-ray scans of 71 GCTBs arising in long bones were retrospectively reviewed. The tumor locations were the distal femur in 31 cases, proximal femur in 11 cases, proximal tibia in 13 cases, distal radius in 6 cases, proximal humerus in 5 cases and proximal fibula in 5 cases. The vertical center (VC) of the tumor was determined with X-ray anteroposterior view, and the correlation between the $\mathrm{VC}$ and the epiphyseal line, and between the distance from the epiphyseal line to the $\mathrm{VC}$ and tumor area or volume were analyzed using a regression model equation based on scatter plot diagrams. The VC of the tumor was located in the metaphyseal region in 57 cases, in the epiphyseal line in 11 cases and in the epiphyseal region in 3 cases. In cases of GCTB located in the distal femur or proximal tibia, significant correlations between the distance from the $\mathrm{VC}$ to the epiphyseal line and tumor area or volume were identified. The site of origin of GCTB was estimated to be located in the metaphyseal region. GCTB often occurs in mature patients, which renders it challenging to estimate the true site of origin of this lesion, since the metaphyseal line has disappeared in mature patients. The results of the present study suggest that GCTB possibly originates in the metaphyseal region.
\end{abstract}

\section{Introduction}

Giant cell tumor of bone (GCTB) is a relatively uncommon primary bone tumor that exhibits an aggressive character

Correspondence to: Professor Yoshihiro Nishida, Department of Orthopedic Surgery, Nagoya University Graduate School of Medicine, 65 Tsurumai, Showa, Nagoya, Aichi 466-8550, Japan

E-mail: ynishida@med.nagoya-u.ac.jp

Key words: giant cell tumor of bone, long bones, origin, metaphysis, radiograph and a high risk of local recurrence following surgery. GCTB accounts for $4-5 \%$ of all primary bone tumors and $13-20 \%$ of all benign bone tumors $(1,2)$. These tumors frequently occur in skeletally mature persons, with a peak incidence in the third to fourth decade of life, while rarely arise in patients with an open growth plate. In addition, GCTBs display a slight female preponderance (3). The majority of GCTBs follow a benign course. However, GCTBs often exhibit local recurrence following surgery (3), and a previous study reported that pulmonary metastases develop despite the presence of benign histological features in 3\% of patients with GCTB (4). GCTBs may undergo malignant transformation (3). Rock et al (5) reported that this may occur as a result of dedifferentiation of the primary tumor, or secondary to prior radiation therapy.

The majority of GCTBs are located at the end of long bones, and $\sim 50 \sim 60 \%$ of them are located around the knee, distal femur and proximal tibia, being the distal femur the bone most frequently involved (6-8).

A previous study described that GCTB arises in the epiphyseal region of long tubular bones (9). The recent literature states that the majority of GCTBs exhibit a typical metaphyseal/epiphyseal location (10), whereas GCTBs may be centered in the metaphysis in children with open physes (11). However, no studies have ever been conducted to determine precisely the site of origin of GCTB. Thus, the purpose of the present study was to determine the site of origin of GCTB of the extremities and to analyze the pattern of progression in GCTB of long bones.

\section{Materials and methods}

A total of 128 patients were diagnosed with GCTB at Nagoya University Graduate School of Medicine (Nagoya, Japan) between October 1977 and September 2011. Of these, GCTB cases with location in the pelvis, vertebrae and small long bones (11 cases), as well as rare sites such as the distal tibia, distal humerus and proximal radius ( 7 cases) were excluded. Recurrent cases at initial referral (21 cases) and cases with insufficient X-ray data (18 cases) were also excluded. Metabolic bone diseases or brown tumors based on hyperparathyroidism were not included in the study. In total, 71 patients (50 males and 21 females) who were pathologically diagnosed with GCTB and subsequently treated at Nagoya University Graduate School of Medicine were enrolled in the present 
study, which was approved by the Institutional Review Board of Nagoya University Graduate School of Medicine (approval no. 2013-0134). Written informed consent was obtained from each patient for participation in the study. Patients' X-ray scans (RADREX-i; Toshiba Medical Systems Cororation, Otawara, Japan) conducted at the initial referral were subjected to analysis. The mean age of the patients at diagnosis was 35 years (range, 13-71 years). The tumor locations were the distal femur in 31 cases, the proximal femur in 11 cases, the proximal tibia in 13 cases, the distal radius in 6 cases, the proximal humerus in 5 cases and the proximal fibula in 5 cases.

The size and volume of the tumor were estimated according to the method previously described (12). Briefly, the largest dimensions of the tumor (depth, width and height) were measured, and it was assumed that the tumor was spherical in shape. The vertical center (VC) of the tumor was determined as the center of tumor height on anteroposterior (AP) X-ray views. The trace of the growth plate was also determined with AP views (Fig. 1). The accuracy of the observations conducted with AP X-ray was confirmed to be adequate, since the same results were obtained with computed tomography (CT; Aquilion ${ }^{\mathrm{TM}}$ ONE; Toshiba Medical Systems Corporation) or magnetic resonance imaging (MRI; MAGNETOM Verio; Siemens Healthcare, Erlangen, Germany) (Fig. 2). The absolute intraobserver and interobserver differences were $\leq 1 \mathrm{~mm}$ in $>90 \%$ of cases.

In cases where the $\mathrm{VC}$ was located in the metaphyseal region, the distance from the epiphyseal line to the VC was represented as a positive value, whereas a negative value was assigned when the VC was located in the epiphyseal region. Joint surface was defined as the roentgenographic border of long bones on X-ray AP views. Using these data, a regression model equation was derived from scatter plot diagrams using commercially available software (Excel version 2013, Microsoft Corporation, Redmond, WA, USA; Ekuseru-Toukei version 2012, Social Survey Research Information Co. Ltd., Tokyo, Japan). Prediction of significant correlations between each pair of variables was determined by the value of the Pearson's correlation coefficient (r). The correlation between the changes of a dependent variable (y) and an independent variable ( $\mathrm{x}$ ) was ascertained by a simple linear regression, using $y=a+b x$ as the equation in the regression model, where $a=y$ intercept when $x=0$, and $b$ is the regression coefficient. $\mathrm{P}<0.05$ was considered to indicate a statistically significant difference (13).

\section{Results}

The VC of the tumor was located in the metaphyseal region in 57 cases, in the epiphyseal line in 11 cases and in the epiphyseal region in 3 cases (Table I). The mean distance from the epiphyseal line to the VC was $13.1 \mathrm{~mm}$ (range, -20.0 to $50.0 \mathrm{~mm}$ ). The mean tumor area and volume were $17.8 \mathrm{~cm}^{2}$ (range, 2.4-62.8 $\mathrm{cm}^{2}$ ) and $45.7 \mathrm{~cm}^{3}$ (range, $2.4-209.3 \mathrm{~cm}^{3}$ ), respectively. The mean distance from the joint space to the tumor border of the articular side was $6.2 \mathrm{~mm}$ (range, 1.0-35.0 $\mathrm{mm}$ ) (Table II). In cases of distal femur and proximal tibia, significant associations between the distance from the epiphyseal line to the tumor $\mathrm{VC}$ and the tumor area or volume were observed. The distance between the tumor VC and the epiphyseal line increased with increasing tumor area or volume. In cases of distal femur, the
Table I. Distribution of the vertical center of the tumor in patients with giant cell tumor of bone.

\begin{tabular}{lccc}
\hline Tumor site & Metaphysis & Epiphyseal line & Epiphysis \\
\hline Distal femur & 27 & 3 & 1 \\
Proximal femur & 8 & 2 & 1 \\
Proximal tibia & 11 & 1 & 1 \\
Distal radius & 2 & 4 & 0 \\
Proximal humerus & 5 & 0 & 0 \\
Proximal fibula & 4 & 1 & 0 \\
\hline
\end{tabular}

$\mathrm{r}$ values between the distance from the epiphyseal line to the tumor VC and the tumor area or volume were $0.439(\mathrm{P}<0.001)$ and 0.313 ( $\mathrm{P}=0.001)$, respectively (Fig. 3). Significant correlations were also observed in cases of proximal tibia. The $r$ values between the distance from the epiphyseal line to the tumor VC and the tumor area or volume were $0.332(\mathrm{P}=0.002)$ and $0.276(\mathrm{P}=0.002)$, respectively (Fig. 4). A fitted line corresponding to the regression model equation is represented in the scatter plot diagrams shown in Figs. 3 and 4. The equations obtained for the regression model corresponding to the correlation between the distance from the epiphyseal line to the tumor VC and the tumor area were $y=1.2900+0.4812 x$ in the cases of distal femur, and $y=5.5100+0.4825 x$ in the cases of proximal tibia, where $\mathrm{y}$ is the tumor $\mathrm{VC}$ in $\mathrm{mm}$ and $\mathrm{x}$ is the tumor area in $\mathrm{cm}^{2}$. The equations obtained for the regression model evaluating the correlation between the distance from the epiphyseal line to the tumor VC and the tumor volume were $y=4.4200+0.1209 x$ for distal femur and $y=7.800+0.1339 x$ for proximal tibia, where $\mathrm{y}$ is the tumor $\mathrm{VC}$ in $\mathrm{mm}$ and $\mathrm{x}$ is the tumor volume in $\mathrm{cm}^{3}$. If the tumor volume in the distal femur is hypothesized to be $0 \mathrm{~cm}^{3}$, the tumor $\mathrm{VC}$ is assumed to be located in the metaphyseal region, at $4.4 \mathrm{~mm}$ distance from the growth plate. If the tumor volume in the proximal tibia is hypothesized to be $0 \mathrm{~cm}^{3}$, the tumor $\mathrm{VC}$ is assumed to be located in the metaphyseal region, at $7.8 \mathrm{~mm}$ distance from the growth plate. These findings suggest the site of origin of GCTB to be the metaphyseal region. No significant associations between the distance from the epiphyseal line to the tumor VC and the tumor area or volume were observed in cases of GCBT located in the proximal femur $(\mathrm{P}=0.309$ and $\mathrm{P}=0.32)$, distal radius $(\mathrm{P}=0.512$ and $\mathrm{P}=0.506)$, proximal humerus $(\mathrm{P}=0.089$ and $\mathrm{P}=0.172)$ or proximal fibula $(\mathrm{P}=0.505$ and $\mathrm{P}=0.505)$. Regarding the distance from the joint space to the tumor border, no associations between the distance from the joint surface to the tumor border and the tumor area or volume were observed in cases of distal femur $(\mathrm{P}=0.536$ and $\mathrm{P}=0.903$, respectively, Fig. 5). Similarly, no associations were observed in cases of proximal tibia (tumor area, $\mathrm{P}=0.526$; tumor volume, $\mathrm{P}=0.555$, Fig. 6 ). No associations were observed either in cases of proximal femur $(\mathrm{P}=0.785$ and $\mathrm{P}=0.636)$, distal radius $(\mathrm{P}=0.414$ and $\mathrm{P}=0.543)$, proximal humerus $(\mathrm{P}=0.182$ and $\mathrm{P}=0.559)$ or proximal fibula $(\mathrm{P}=0.559$ and $\mathrm{P}=0.559)$.

In addition, a significant association between patients' age and tumor area or volume was observed only in cases of proximal tibia, whereas no association was observed in any of the other cases. 
Table II. Mean distance from the epiphyseal line to the tumor VC, tumor area, tumor volume and distance from the joint surface to the tumor border in patients with giant cell tumor of bone.

\begin{tabular}{lcccc}
\hline Tumor site & $\begin{array}{c}\text { Epiphyseal line to } \\
\text { VC, } \mathrm{mm} \text { (range) }\end{array}$ & $\begin{array}{c}\text { Tumor area, } \\
\mathrm{cm}^{2} \text { (range) }\end{array}$ & $\begin{array}{c}\text { Tumor volume, } \\
\mathrm{cm}^{3} \text { (range) }\end{array}$ & $\begin{array}{c}\text { Joint surface to tumor } \\
\text { border, mm (range) }\end{array}$ \\
\hline Distal femur & $11.7(-5.0$ to 25.0$)$ & $21.6(5.9-62.8)$ & $60.3(11.8-209.3)$ & $4.9(1.0-10.0)$ \\
Proximal femur & $19.0(-20.0$ to 50.0$)$ & $17.8(4.7-42.4)$ & $37.8(11.0-84.8)$ & $12.8(1.0-35.0)$ \\
Proximal tibia & $13.6(-10.0$ to 40.0$)$ & $16.8(3.1-56.5)$ & $43.3(5.2-169.6)$ & $5.2(1.0-10.0)$ \\
Distal radius & $1.3(0.0-5.0)$ & $4.6(2.4-9.6)$ & $6.6(2.4-16.0)$ & $1.7(1.0-3.0)$ \\
Proximal humerus & $23.6(20.0-30.0)$ & $18.0(7.9-31.4)$ & $48.6(13.1-91.6)$ & $10.6(10.0-13.0)$ \\
Proximal fibula & $12.0(0.0-25.0)$ & $12.3(7.9-20.4)$ & $22.9(10.5-40.8)$ & $2.8(1.0-10.0)$ \\
All cases & $13.1(-20.0$ to 50.0$)$ & $17.8(2.4-62.8)$ & $45.7(2.4-209.3)$ & $6.2(1.0-35.0)$ \\
\hline
\end{tabular}

$\mathrm{VC}$, vertical center.
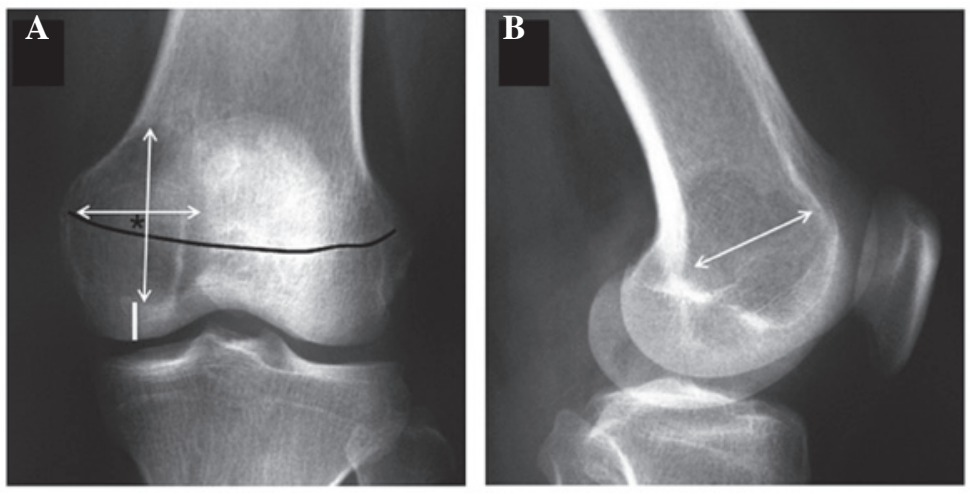

Figure 1. Schematic illustration of tumor measurement using X-rays. (A) Anteroposterior and (B) lateral views were used for measuring the largest dimensions of the tumor (depth, width and height) (white lines with arrows), distance from the joint surface to the tumor border (white thick line), vertical center of the tumor (") and trace of growth plate (black line).
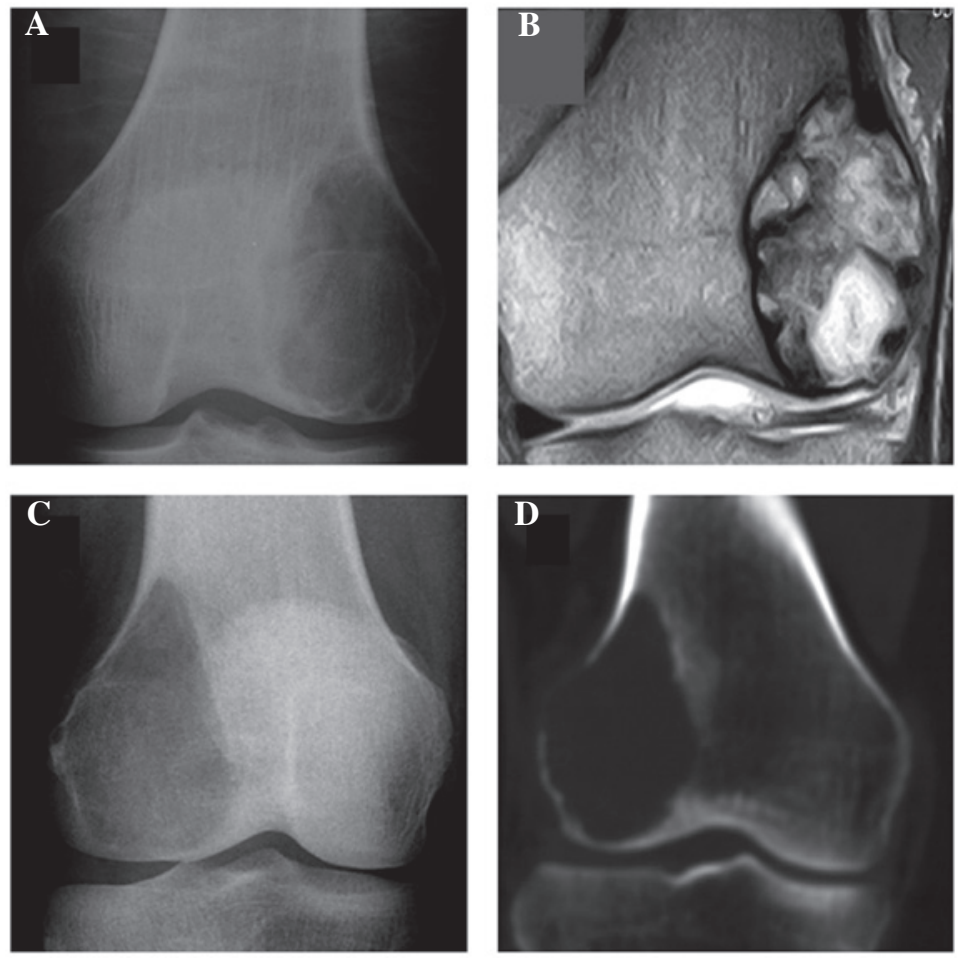

Figure 2. Representative images of two cases of giant cell tumor of bone arising in the distal femur. (A) AP X-ray and (B) coronal view of T2-weighted magnetic resonance image of a 20 -year-old male patient. (C) AP X-ray and (D) coronal view of computed tomography image of a 33-year-old female patient. AP, anteroposterior. 
A

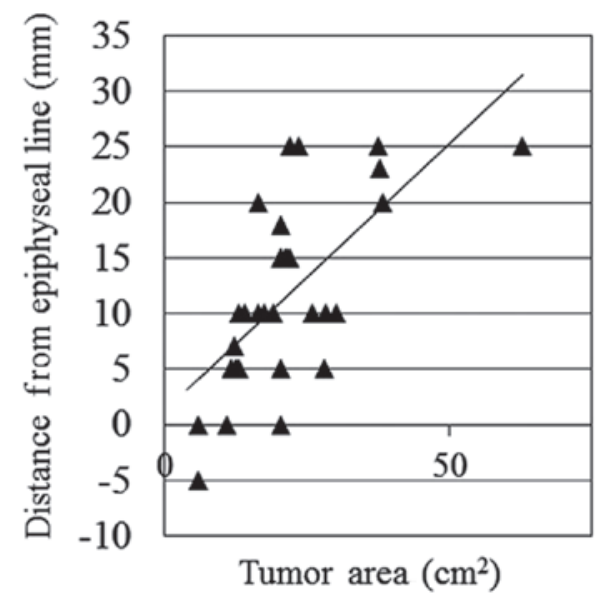

B

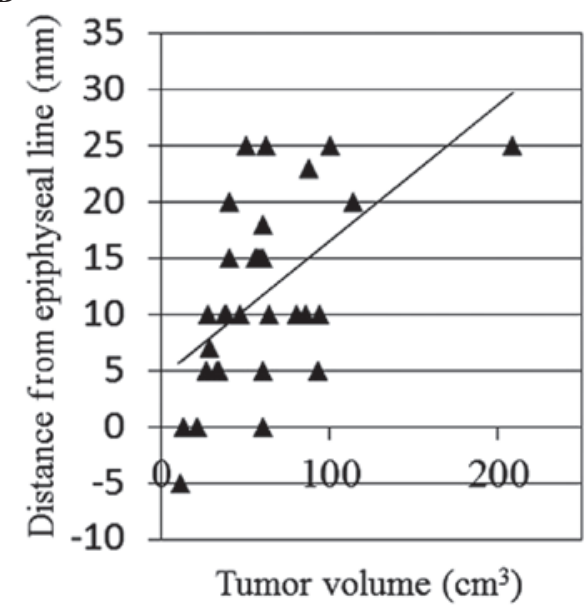

Figure 3. Scatter plot diagrams and regression analysis of tumors arising in the distal femur. (A) Correlation between the tumor area and the distance from the epiphyseal line to the tumor $\mathrm{VC}$ (model equation, $\mathrm{y}=1.2900+0.4812 \mathrm{x} ; \mathrm{r}=0.439 ; \mathrm{P}<0.001)$. (B) Correlation between the tumor volume and the distance from the epiphyseal line to the tumor VC (model equation, $\mathrm{y}=4.4200+0.1209 \mathrm{x} ; \mathrm{r}=0.313 ; \mathrm{P}=0.001)$. VC, vertical center.

A

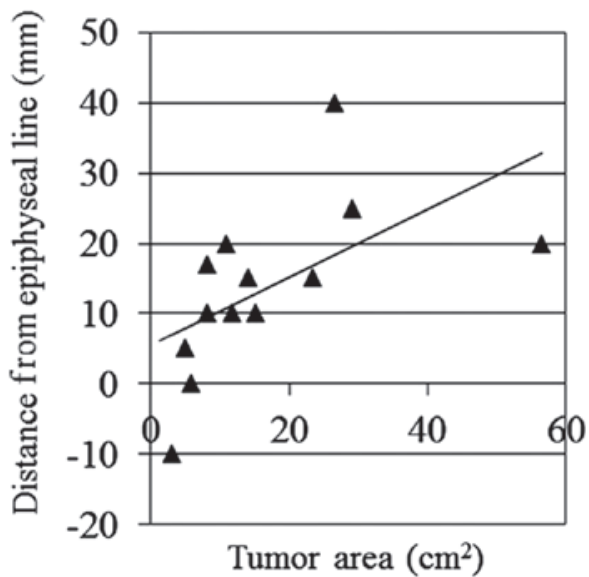

B

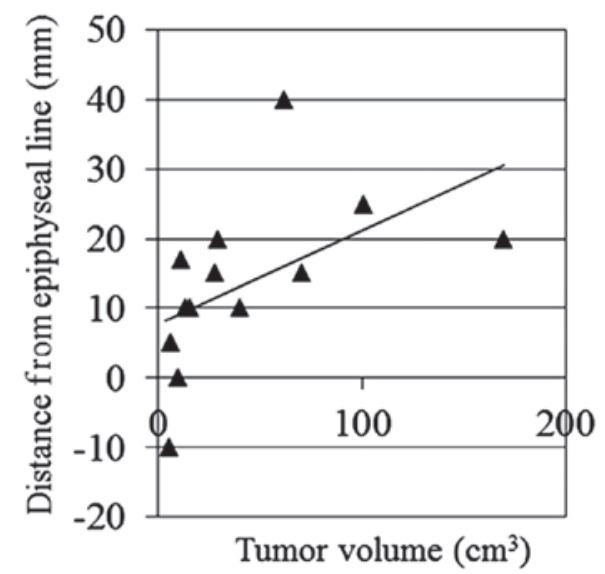

Figure 4. Scatter plot diagrams and regression analysis of tumors arising in the proximal tibia. (A) Correlation between the tumor area and the distance from the epiphyseal line to the tumor VC (model equation, $\mathrm{y}=5.5100+0.4825 \mathrm{x} ; \mathrm{r}=0.332 ; \mathrm{P}=0.002$ ). (B) Correlation between the tumor volume and the distance from the epiphyseal line to the tumor $\mathrm{VC}$ (model equation, $\mathrm{y}=7.8000+0.1339 \mathrm{x} ; \mathrm{r}=0.276 ; \mathrm{P}=0.002)$. VC, vertical center.

\section{Discussion}

To the best of our knowledge, the results of the present study suggest for the first time the site of origin of GCTB to be the metaphyseal region, using equations fitted to regression models. The exact site of origin of GCT remains controversial. Murphey et al (14) reported that in skeletally immature patients, GCTBs were located in metaphyseal rather than meta-epiphyseal bone, with an open epiphyseal plate acting as a barrier to tumor growth. Fain et al (15) reported non-epiphyseal GCTB of long bones. Of 1,682 cases of GCTB reported by the authors, only $14(0.8 \%)$ were located in exclusively metaphyseal or diaphyseal regions. A notable finding of that study was the fact that the majority of patients with non-epiphyseal GCTB were $<15$ year-old (15). These unusual cases raised debate as to whether GCTB is capable of developing in the epiphysis $(6,9)$ or in the metaphysis, with subsequent extension to the epiphysis following growth plate closure (16-18). Gandhe et al (19) reported cases of epiphyseal GCTB. However, considering that
GCTB is occasionally misdiagnosed or confused with other giant cell-rich tumors, other giant cell-containing tumors such as giant cell-rich osteosarcoma and chondroblastoma should be strictly differentiated from epiphyseal GCTB by experienced pathologists (3).

The current study revealed that the distance between the joint surface and the tumor border of the articular side is short, even in cases of small tumors. These results are consistent with those reported by Murphey et al (14), whereby 84-99\% of lesions extended to locations within $1 \mathrm{~cm}$ of subarticular bone (14). Suzuki et al (20) reported that less residual thickness of subarticular bone correlated with higher recurrence following surgery for GCTB, and tended to be associated with secondary osteoarthritis. Thus, it may be hypothesized that early diagnosis may lead to preservation of a sufficient quantity of subchondral bone, and as a result, the rate of local recurrence may decrease and the functional outcome may improve. However, the biological character of GCTB, which easily extends to the articular side (epiphyseal region) of the 
A

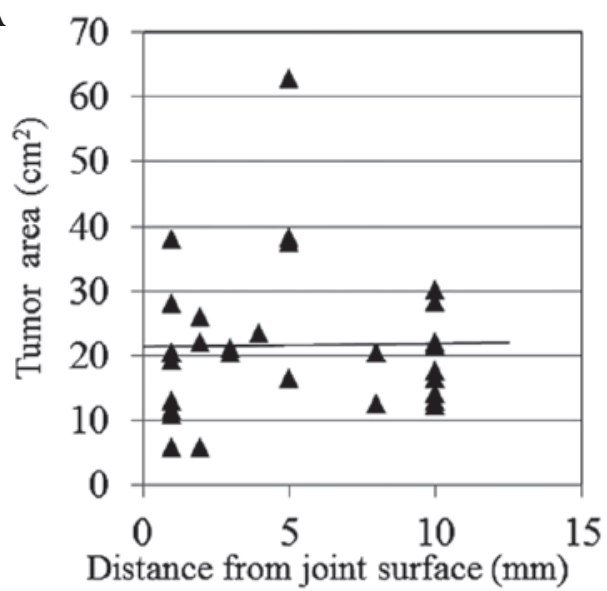

B

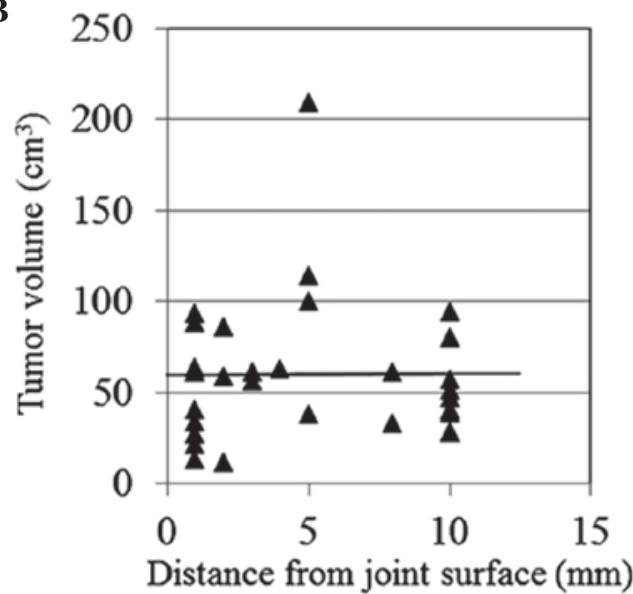

Figure 5. Scatter plot diagrams and regression analysis of tumors arising in the distal femur. (A) Correlation between the tumor area and the distance from the joint surface to the tumor border (model equation, $\mathrm{y}=4.5900+0.0090 \mathrm{x} ; \mathrm{r}=0.001 ; \mathrm{P}=0.536$ ). (B) Correlation between the tumor volume and the distance from the joint surface to the tumor border (model equation, $\mathrm{y}=4.9000+0.0001 \mathrm{x} ; \mathrm{r}=0.000 ; \mathrm{P}=0.903$ ).

A

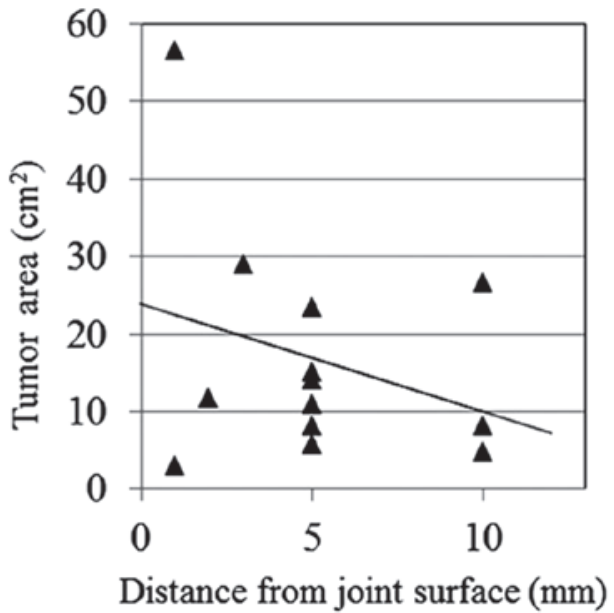

B

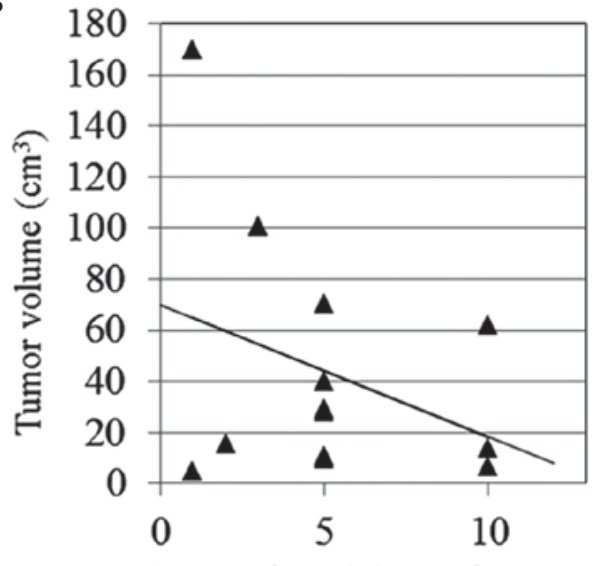

Distance from joint surface (mm)

Figure 6. Scatter plot diagrams and regression analysis of tumors arising in the proximal tibia. (A) Correlation between the tumor area and the distance from the joint surface to the tumor border (model equation, $\mathrm{y}=6.2600-0.0660 \mathrm{x} ; \mathrm{r}=0.092 ; \mathrm{P}=0.526$ ). (B) Correlation between the tumor volume and the distance from the joint surface to the tumor border (model equation, $\mathrm{y}=6.1400-0.0227 \mathrm{x} ; \mathrm{r}=0.120 ; \mathrm{P}=0.555$ ).

affected long bones, difficulties the reduction of the recurrence rate and induces the development of postoperative osteoarthritic changes.

Gandhe et al (19) and Kransdorf et al (21) reported that GCTB lesions involve the metaphysis rather than the epiphysis in skeletally immature patients, since the open epiphyseal plate acts as a barrier to tumor growth. Puri et al (22) noted that an open physis did not prevent GCTBs from penetrating the epiphyseal cartilage. Campanacci et al (23) observed invasion of the joint in only $5 \%$ of GCTB cases. Based on these previous reports, it may be proposed that the expansion of GCTBs is partly inhibited by the presence of articular cartilage or an open growth plate. As indicated in the current study, GCTB appears to arise at a metaphyseal site and extend in a diaphyseal and epiphyseal direction. There was observed to be no barrier in the diaphysis against tumor extension, whereas tumor growth was inhibited by articular cartilage. As a result, the tumor VC may shift slowly in a diaphyseal direction. However, the site of origin of GCTB is suggested to be the metaphyseal region, according to the regression model equations discussed in the present study.

There are a number of limitations affecting the current study. First, a relatively small number of patients were included in the study, which may be underpowered to obtain more meaningful results regarding the original site of GCTBs. Second, it is not possible to analyze or explain the site-specific differences observed in the present study, since the location of GCTBs in the proximal femur, distal radius and proximal fibula should be analyzed in a larger number of cases, based on multicenter analyses. Third, other radiological modalities including CT or MRI may evaluate more precisely the VC of GCTBs than X-rays, although, as demonstrated in the present study, AP X-rays were able to evaluate the center of tumor as adequately as CT or MRI. Fourth, a tumor is unable to extend to the articular side once it reaches the subchondral region, possibly biasing the results of the current analyses. However, the significant correlations obtained with the regression model equations suggest the reliability of the present results. 
In conclusion, the findings of the present study indicate that the site of origin of GCTB is possibly the metaphyseal region. The results of the current study provide useful information regarding the clinical course of GCTB for physicians, and suggest that early detection may be crucial to cure this refractory benign tumor.

\section{Acknowledgements}

The authors would like to thank Miss Eri Ishihara (Department of Orthopedic Surgery, Nagoya University Graduate School of Medicine) for her secretarial assistance during the present study, and Dr Satoshi Yamashita (Department of Orthopedic Surgery, Nagoya University Graduate School of Medicine) for his support with statistical analyses. The present study was partly funded by the Ministry of Education, Culture, Sports, Science and Technology of Japan [Tokyo, Japan; grant-in-aid no. 262933341 for Scientific Research (B)] and partly by the National Cancer Center Research and Development Fund (Tokyo, Japan; grant no. 26-A-4).

\section{References}

1. Chakarun CJ, Forrester DM, Gottsegen CJ, Patel DB, White EA and Matcuk GR Jr: Giant cell tumor of bone: Review, mimics, and new developments in treatment. Radiographics 33: 197-211, 2013.

2. Niu X, Zhang Q, Hao L, Ding Y, Li Y, Xu H and Liu W: Giant cell tumor of the extremity: Retrospective analysis of 621 Chinese patients from one institution. J Bone Joint Surg Am 94: 461-467, 2012.

3. Campanacci M (ed): Giant Cell Tumor. In: Bone and Soft Tissue Tumors. Campanacci M (ed). 2nd edition. Springer, Vienna, pp99-142, 1990.

4. Tubbs WS, Brown LR, Beabout JW, Rock MG and Unni KK: Benign giant-cell tumor of bone with pulmonary metastases: Clinical findings and radiologic appearance of metastases in 13 cases. AJR Am J Roentgenol 158: 331-334, 1992.

5. Rock MG, Sim FH, Unni KK, Witrak GA, Frassica FJ, Schray MF, Beabout JW and Dahlin DC: Secondary malignant giant-cell tumor of bone. Clinicopathological assessment of nineteen patients. J Bone Joint Surg Am 68: 1073-1079, 1986.

6. Dahlin DC, Cupps RE and Johnson EW Jr: Giant-cell tumor: A study of 195 cases. Cancer 25: 1061-1070, 1970.

7. Jiang N, Qin CH, Tan CX, Wen SF, Ma YF, Dong F, Diao XC Zhang P and Yu B: A retrospective analysis of 140 patients with giant cell tumor in the extremity: A multicenter study based on four hospitals in South China. Cancer Epidemiol 37: 294-299, 2013.
8. Saikia KC, Bhuyan SK, Borgohain M, Saikia SP, Bora A and Ahmed F: Giant cell tumour of bone: An analysis of 139 Indian patients. J Orthop Sci 16: 581-588, 2011.

9. Goldenberg RR, Campbell CJ and Bonfiglio M: Giant-cell tumor of bone. An analysis of two hundred and eighteen cases. J Bone Joint Surg Am 52: 619-664, 1970.

10. Turcotte RE: Giant cell tumor of bone. Orthop Clin North Am 37: 35-51, 2006

11. Raskin KA, Schwab JH, Mankin HJ, Springfield DS and Hornicek FJ: Giant cell tumor of bone. J Am Acad Orthop Surg 21: 118-126, 2013.

12. Jeys LM, Suneja R, Chami G, Grimer RJ, Carter SR and Tillman RM: Impending fractures in giant cell tumours of the distal femur: Incidence and outcome. Int Orthop 30: 135-138, 2006.

13. Mondal MK, Jana TK, Giri Jana S and Roy H: Height prediction from ulnar length in females: A study in Burdwan district of West Bengal (regression analysis). J Clin Diagn Res 6: 1401-1404, 2012.

14. Murphey MD, Nomikos GC, Flemming DJ, Gannon FH, Temple HT and Kransdorf MJ: From the archives of AFIP. Imaging of giant cell tumor and giant cell reparative granuloma of bone: Radiologic-pathologic correlation. Radiographics 21: 1283-1309, 2001

15. Fain JS, Unni KK, Beabout JW and Rock MG: Nonepiphyseal giant cell tumor of the long bones. Clinical, radiologic and pathologic study. Cancer 71: 3514-3519, 1993.

16. Campanacci M, Giunti A and Olmi R: Giant-cell tumors of bone. A study of 209 cases with long term follow up in 130. Ital J Orthop Traumatol 1: 249-277, 1975.

17. Peison B and Feigenbaum J: Metaphyseal giant-cell tumor in a girl of 14. Radiology 118: 145-146, 1976.

18. Rietveld LA, Mulder JD, Brûtel de la Rivière $G$ and van Rijssel TG: Giant cell tumour: Metaphyseal or epiphyseal origin? Diagn Imaging 50: 289-293, 1981.

19. Gandhe A, Sankhe A, Aeron G and Joshi A: Epiphyseal giant cell tumour in an immature skeleton. Br J Radiol 81: e75-e78, 2008.

20. Suzuki Y, Nishida Y, Yamada Y, Tsukushi S, Sugiura H, Nakashima $\mathrm{H}$ and Ishiguro $\mathrm{N}$ : Re-operation results in osteoarthritic change of knee joints in patients with giant cell tumor of bone. Knee 14: 369-374, 2007.

21. Kransdorf MJ, Sweet DE, Buetow PC, Giudici MA and Moser RP Jr: Giant cell tumor in skeletally immature patients. Radiology 184: 233-237, 1992.

22. Puri A, Agarwal MG, Shah M, Jambhekar NA, Anchan C and Behle S: Giant cell tumor of bone in children and adolescents. J Pediatr Orthop 27: 635-639, 2007.

23. Campanacci M, Baldini N, Boriani S and Sudanese A: Giant-cell tumor of bone. J Bone Joint Surg Am 69: 106-114, 1987. 